Meta

Journal des tradlucteurs

Translators' Journal

Robin Setton (1999): Simultaneous Interpretation: A Cognitive and Pragmatic Analysis, Amsterdam and Philadelphia, John Benjamins, 399 p.

\title{
Linda Anderson
}

Volume 45, numéro 4, décembre 2000

URI : https://id.erudit.org/iderudit/001886ar

DOI : https://doi.org/10.7202/001886ar

Aller au sommaire du numéro

Éditeur(s)

Les Presses de l'Université de Montréal

\section{ISSN}

0026-0452 (imprimé)

1492-1421 (numérique)

Découvrir la revue

\section{Citer ce compte rendu}

Anderson, L. (2000). Compte rendu de [Robin Setton (1999): Simultaneous

Interpretation: A Cognitive and Pragmatic Analysis, Amsterdam and

Philadelphia, John Benjamins, 399 p.] Meta, 45(4), 672-673.

https://doi.org/10.7202/001886ar d'utilisation que vous pouvez consulter en ligne.

https://apropos.erudit.org/fr/usagers/politique-dutilisation/ 


\title{
Comptes rendus
}

\author{
Robin Setton (1999): Simultaneous Interpretation: A Cognitive and Pragmatic \\ Analysis, Amsterdam and Philadelphia, John Benjamins, 399 p.
}

The two "ambitions" of this ambitious, exploratory work are laid down at the outset: "to update the state of the art in research on simultaneous interpretation with contributions from modern linguistics and cognitive theory... and [...] to demonstrate the value of T/\&/I data to the study of language and the mind." In its attempts to mitigate the polarization in simultaneous interpretation (SI) research which has commonly pitted SI practitioners against cognitive scientists, as well as in its incorporation of modern pragmatic theory into a linguistic-cognitive analysis of SI, it makes an invaluable contribution. The reviewer is in substantial agreement with the goals and the positions of the author. The author is also to be highly commended for the wealth of research, in an extensive variety of disciplines, that went into the making of the book. Attempting to integrate findings from such an array of areas of inquiry and to put them in representational terms - in a coherent and readily intelligible fashion-is (as the author acknowledges) a substantial challenge. Unfortunately, the book's efforts are not up to this challenge. In its desire for comprehensiveness, its presentation is disjointed and the work is a forbidding read.

It features a "provisional" and "hybrid" model of the SI act, which attempts to show graphically the "incremental assembly of meaning over a string of incoming discourse.” It seeks to integrate three variables included in existing SI models—subjective knowledge, on-line strategies and stylistic preference-into a unifying characterization of SI performance which combines linguistic-processing models with cognitive and pragmatic principles. Mental Models theory, a cornerstone of the characterization, rightly proposes that the mind of the interpreter does not merely 'receive' concepts, percepts and affect: it builds up representations (models) on the basis of its own individual prism of concepts, percepts and affect. Not an in vitro exercise, SI attempts to identify with the Speaker's intentions, attitudes and content through a process of exploiting available evidence. The array of available evidence allows the interpreter to begin building a mental model of each portion of discourse even before its representation is complete in the Speaker's speech.

Extensive studies of corpora of German-English and Chinese-English simultaneous intepretations then follow. As such they present the difficulty of all corpus studies - the need to pare down voluminous data and to provide clear examples illuminating each point. A compound difficulty is, however, the rarity of clear, concise sentences, the language a dense thicket of jargon (this book boasts a glossary 17 pages long). The corpus analyses, which comprise the bulk of the work, are its least reader-friendly portion. Sentence segments are also extracted, analyzed and commented upon in such minute detail that this reviewer found it a challenge to follow the thread of the arguments. Disquisitions on diverse underlying theories 
obtrude on the flow of these arguments. Expositions - of the constrasting linguistics of German, Chinese and English, or their comparative stylistics and semantics, of context effects or of sentence comprehension pragmatics-are presented in numbing detail and interspersed throughout what should be the focus-comparative analyses of the source and intepreted versions as they unwind. In countless places the reader is required to refer back to parsing analyses/comparisons presented elsewhere but not made available again for easy comprehension. Unnecessary tables intrude, for instance, on the concept of inference as it operates in SI, while on several occasions reference is made to a Figure 3.3, which a hunt further back in the book revealed did not exist. The detail is so great that the woods frequently vanish behind the trees.

A further level of SI analysis is featured, one oft-mentioned in SI literature but more to postulate its existence than to depict its operation in the SI act. This level is the well-known concept of a "meta-language", an intermediate conceptual language postulated to bridge the gap between the source speech-with its mesh of intentionality, attitudes and propositional content-and the interpreted speech. In the model it is formalized as "a kind of language of thought" (LOT). The author is again to be commended for her willingness to tackle this issue, but including representations of "LOT" relations within the same already overburdened coding of unfolding input and output excerpts further exacerbates the model's untidiness.

The author's second ambition, to apply insights from SI research to an understanding of language as it is used, is methodologically compromised: the model is based on the speech of only 5 interpreters (for the main experimental corpus), a sample size from which it would be rash to generalize. Conclusions are drawn regarding how interpreters handle problematic parts of speech in renditions of German and Chinese source speech, and attempts are made to distinguish at what point failures (undefined) occur in SI, on the basis of only a handful of interpreters interpreting from two languages. Already few, the subjects on which the generalizations are based are also a diverse lot, showing different degrees of familiarity with their target language and different years of experience in interpretation in general. Any LOT in SI obviously differs with the extent or depth of one's experience of transforming the input into output. Is thought in the constrained and paced task of SI at all comparable to free-flowing thought? Further, in only one case was the SI situation not simulated. The author comments briefly on "differences" observed between interpreted versions at the one, live interpretation event versus interpretation performed during simulations. This reviewer has observed a wide variety in subject reactions to simulated interpretation sessions, just one being in the extent to which they apply themselves to the task.

In concept, the author's model is immensely valuable and this book needs to be written. The wealth of research is awe-inspiring. This book, however, is forbiddingly dense and the density is aggravated by the absence of a clear marshaling of its arguments. The reviewer would like to see this wonderful research presented in more reader-friendly language and a more cohesive/coherent format, carrying the reader step by step through the sections of a (re-engineered) model, while clearly separating out underlying theory from corpus analysis. 